\title{
Cobalt internal standard for Ni to assist the simultaneous determination of Mo and Ni in plant materials by high-resolution continuum source graphite furnace atomic absorption spectrometry employing direct solid sample analysis
}

\author{
Diego Victor de Babos a , Marcos André Bechlin ${ }^{\mathrm{a}}$, Ariane Isis Barros ${ }^{\mathrm{a}}$, \\ Edilene Cristina Ferreira ${ }^{a}$, José Anchieta Gomes Neto ${ }^{a, *}$, Silvana Ruella de Oliveira ${ }^{b}$ \\ a São Paulo State University-Unesp, Analytical Chemistry Department, P.O. Box 355, 14801-970 Araraquara, SP, Brazil \\ b University of São Paulo-USP, FFCLRP, Department of Chemistry, 14040-901, Ribeirão Preto, SP, Brazil
}

\section{A R T I C L E I N F O}

\section{Article history:}

Received 18 November 2015

Received in revised form

17 February 2016

Accepted 19 February 2016

Available online 21 February 2016

\section{Keywords:}

Micronutrients

Molybdenum

Nickel

High-resolution continuum source graphite

furnace atomic absorption spectrometry

Direct solid sample analysis

Internal standardization

\begin{abstract}
A B S T R A C T
A new method is proposed for the simultaneous determination of Mo and Ni in plant materials by highresolution continuum source graphite furnace atomic absorption spectrometry (HR-CS GFAAS), employing direct solid sample analysis (DSS) and internal standardization (IS). Cobalt was used as internal standard to minimize matrix effects during Ni determinations, enabling the use of aqueous standards for calibration. Correlation coefficients for the calibration curves were typically better than 0.9937 . The performance of the method was checked by analysis of six plant certified reference materials, and the results for Mo and Ni were in agreement with the certified values (95\% confidence level, $t$-test). Analysis was made of different types of plant materials used as renewable sources of energy, including sugarcane leaves, banana tree fiber, soybean straw, coffee pods, orange bagasse, peanut hulls, and sugarcane bagasse. The concentrations found for Mo and Ni ranged from 0.08 to $0.63 \mathrm{ng} \mathrm{mg}^{-1}$ and from 0.41 to $6.92 \mathrm{ng} \mathrm{mg}^{-1}$, respectively. Precision (RSD) varied from $2.1 \%$ to $11 \%$ for Mo and from $3.7 \%$ to $10 \%$ for $\mathrm{Ni}$. Limits of quantification of 0.055 and $0.074 \mathrm{ng}$ were obtained for Mo and $\mathrm{Ni}$, respectively.
\end{abstract}

(c) 2016 Elsevier B.V. All rights reserved.

\section{Introduction}

The world's growing demand for food, animal feed, biofuels, and biomass is expected to increase not only the production of agricultural crops, but also their productivity. Foliar diagnosis is a routine management practice used to optimize mineral nutrition of plants, crop production, and productivity [1,2]. The analysis of nutrients in leaves normally involves the measurement of the macronutrients $\mathrm{K}, \mathrm{Ca}, \mathrm{Mg}, \mathrm{N}, \mathrm{P}$, and $\mathrm{S}$, and the micronutrients $\mathrm{B}, \mathrm{Co}$, $\mathrm{Cl}, \mathrm{Cu}, \mathrm{Fe}, \mathrm{Mn}$, and $\mathrm{Zn}$ [3]. More recently, the roles of Mo and $\mathrm{Ni}$ in biological nitrogen fixation have been identified [3-8], and these elements have been added to the list of required plant nutrients. Although fertilizers are an important factor in crop production, their indiscriminate use can contribute to the accumulation of nutrients in terrestrial and aquatic ecosystems, causing severe environmental damage $[9,10]$. The monitoring of Mo and $\mathrm{Ni}$ in plant tissues may assist in achieving greater efficiency in nitrogen

\footnotetext{
* Corresponding author.

E-mail address: anchieta@iq.unesp.br (J.A.G. Neto).
}

fertilizer usage; this would be economically and ecologically attractive, because external nitrogen inputs could be reduced and the use of available resources could be maximized.

Graphite furnace atomic absorption spectrometry (GFAAS) is among the main spectrometric techniques commonly used to determine Mo and $\mathrm{Ni}$ at trace levels in complex matrices such as plant tissues [11,12]. Besides offering high levels of sensitivity and selectivity, GFAAS is suitable for direct solid sample analysis, because the atomizer allows the decomposition and elimination of the sample matrix, together with the production of free gaseous atoms of the analyte, without the need for previous treatment of the samples $[13,14]$. Minimal sample pretreatment, lower risks of contamination and analyte losses, increased sensitivity, faster analytical frequency, low consumption of reagents, and minor generation of wastes are among the main advantages of direct solid sample analysis (DSS) [15]. The high-resolution continuum source graphite furnace atomic absorption spectrometry technique (HR-CS GFAAS) can extend the applicability of DSS, due to the ability to (i) correct the structured background contribution using least-squares background correction (LSBC); (ii) improve the 
visibility of the spectral environment at high resolution; (iii) provide higher signal-to-noise ratios than obtained using line sources; (iv) integrate the absorbance measurements around the line core, or sum of the absorbances for different lines; ( $v$ ) extend the linear working range by measuring at alternative lines; and (vi) incorporate an automatic solid sampler and a microbalance, decreasing errors caused by manual operations [16-19].

Despite the advantages offered by DSS HR-CS GFAAS, interferences due to the sample matrix are often observed, making it difficult to use conventional aqueous calibration. In addition, other factors such as errors associated with sampling can reduce the precision and accuracy of the method. The internal standardization (IS) calibration method, routinely used in mass and atomic spectrometric techniques [20], can assist in minimizing uncertainties inherent to trace analysis. The main prerequisites for selection of an internal standard are: similar physicochemical properties of the analyte and the internal standard; ability to perform simultaneous measurements; and absence of spectral interference caused by the internal standard. In HR-CS GFAAS, these prerequisites can be enhanced by using appropriate lines for $\mathrm{Co}, \mathrm{Ni}$, and Mo. However, despite the benefits of using IS in DSS HR-CS GFAAS, the literature contains few reports of its application.

Given the above considerations, the present work describes the simultaneous determination of Mo and $\mathrm{Ni}$ in plant materials by DSS HR-CS GFAAS, employing Co as internal standard to reduce matrix effects during Ni determinations. The efficiency of the proposed method was evaluated by analysis of certified reference materials.

\section{Experimental}

\subsection{Instrumentation}

Absorbance measurements of Co, Mo, and Ni were carried out using an Analytik Jena ContrAA 700 graphite furnace atomic absorption spectrometer (Jena, Germany) equipped with a xenon short-arc lamp operating in "hot-spot" mode as continuum radiation source, a high-resolution double monochromator, and a charge-coupled device (CCD) detector. The analytical lines selected for the absorbance measurements were at $313.221 \mathrm{~nm}$ (Co), $313.259 \mathrm{~nm}$ (Mo), and $313.410 \mathrm{~nm}(\mathrm{Ni})$, with peak volume selected absorbance (PVSA) [18] of 3 pixels ( $\mathrm{CP} \pm 1$, where CP is the measurement at the line core). The graphite furnace heating program employed for the simultaneous measurements of $\mathrm{Co}, \mathrm{Mo}$, and $\mathrm{Ni}$ is shown in Table 1. Transversely heated pyrolytic graphite-coated solid sampling tubes (without a dosing hole) were used throughout the work. Samples were weighed directly onto a Sartorius WZ2PW micro-balance (Göttingen, Germany) with a precision of $0.001 \mathrm{mg}$. Solid sampling platforms were inserted into the graphite furnace using an Analytik Jena SSA 600 automated solid sampler. High purity argon (99.999\%, White Martins, Sertãozinho, Brazil) was used as the purge and protective gas.

Table 1

Heating program of graphite furnace used for simultaneous determination of Mo and $\mathrm{Ni}$ in plant materials using DSS HR-CS GFAAS.

\begin{tabular}{lclll}
\hline Step & Temperature $\left({ }^{\circ} \mathrm{C}\right)$ & $\begin{array}{l}\text { Ramp } \\
\left({ }^{\circ} \mathrm{C} \mathrm{s}^{-1}\right)\end{array}$ & $\begin{array}{l}\text { Hold time } \\
(\mathrm{s})\end{array}$ & $\begin{array}{l}\text { Ar flow-rate } \\
\left(\mathrm{L} \mathrm{min}^{-1}\right)\end{array}$ \\
\hline Drying 1 & 110 & 6 & 10 & 2.0 \\
Drying 2 & 130 & 5 & 10 & 2.0 \\
Pyrolysis & 1600 & 50 & 10 & 2.0 \\
Auto-zero & 1600 & 0 & 5 & 0 \\
Atomization & 2600 & 3000 & 12 & 0 \\
Cleaning & 2650 & 500 & 4 & 2.0 \\
\hline
\end{tabular}

A Wiley cutting mill (TE-648, Tecnal, Piracicaba, Brazil) and a Spex 6800 cryogenic grinding mill (Metuchen, USA) were used to grind the samples.

\subsection{Reagents, analytical solutions, and samples}

All solutions were prepared using high purity water (resistivity 18.2 M $\Omega . \mathrm{cm}$ ) obtained from a Rios $5^{\text {in }}$ reverse osmosis and Milli$\mathrm{Q}^{\mathrm{TM}}$ Academic ${ }^{\mathbb{R}}$ deionizer system (Millipore, Bedford, USA) and Suprapur $^{10}$ nitric acid (Merck, Darmstadt, Germany).

Single element standard stock solutions containing $1000 \mathrm{mg} \mathrm{L}^{-1}$ Co and $\mathrm{Ni}$ and $100 \mathrm{mg} \mathrm{L}^{-1}$ Mo (Specsol, São Paulo, Brazil) were suitably diluted to prepare analytical solutions corresponding to the mass ranges $0-0.33 \mathrm{ng}$ Mo and $0-8.50 \mathrm{ng} \mathrm{Ni}$, together with $500 \mathrm{ng}$ Co as internal standard. The analytical solutions were acidified to $0.1 \%(\mathrm{v} / \mathrm{v}) \mathrm{HNO}_{3}$.

A $2000 \mathrm{mg} \mathrm{L}^{-1} \mathrm{Mg}\left(\mathrm{NO}_{3}\right)_{2}$ modifier solution with $0.05 \%(\mathrm{w} / \mathrm{v})$ of Triton X-100 (Mallincrokdt, Paris, USA) was prepared by dissolution of a suitable amount of $\mathrm{Mg}\left(\mathrm{NO}_{3}\right)_{2} \cdot 6 \mathrm{H}_{2} \mathrm{O}$ (Suprapur ${ }^{\mathbb{R}}$, Merck, Darmstadt, Germany) in water.

All glassware and polypropylene flasks were washed with Ex$\operatorname{tran}{ }^{\circledR}$ laboratory detergent, soaked in $10 \%(\mathrm{v} / \mathrm{v}) \mathrm{HNO}_{3}$ for $24 \mathrm{~h}$, and then rinsed abundantly with deionized water before use.

The certified reference materials (CRMs) 1573a Tomato Leaves, 1515 Apple Leaves, 1572 Citrus Leaves, 1547 Peach Leaves, and 1575a Trace Elements in Pine Needles were obtained from the National Institute of Standards and Technology (Gaithersburg, USA), and the INCT-OBTL-5 Oriental Basma Tobacco Leaves CRM was acquired from the Institute of Nuclear Chemistry and Technology (Warsaw, Poland). Analyses of these CRMs were used to determine the accuracy and precision of the method.

Ten plant materials (banana tree fiber, soybean straw, coffee pods, peanut hulls, sugarcane bagasse, orange bagasse, and sugarcane leaves) were collected in rural areas of the municipality of Araraquara (São Paulo State, Brazil). All samples were dried at $65{ }^{\circ} \mathrm{C}$ for $72 \mathrm{~h}$ in a forced air oven, and then ground in a cutting mill fitted with a 10-mesh screen at the bottom of the cutting chamber. Subsequently, a portion of the sample was placed in a grinding vial, immersed in liquid nitrogen, and ground according to the following five-step program: 2-min sample freezing; 3-min sample grinding; 2 -min sample freezing; 3 -min sample grinding; 2-min sample freezing. This process resulted in particle sizes smaller than $50 \mu \mathrm{m}$.

\subsection{Analytical procedure}

Evaluation of the thermochemical behaviors of $\mathrm{Co}$, Mo, and $\mathrm{Ni}$, together with optimization of the graphite furnace heating program, were carried out using a two-level full factorial design (2, where $\mathrm{n}$ is the number of variables). The variables evaluated, with the corresponding minimum and maximum levels, were as follows: pyrolysis temperature $\left(1400\right.$ and $\left.1600{ }^{\circ} \mathrm{C}\right)$, atomization temperature $\left(2400\right.$ and $2600{ }^{\circ} \mathrm{C}$ ), and the presence of $\mathrm{Mg}\left(\mathrm{NO}_{3}\right)_{2}$ modifier $(0$ and $5 \mu \mathrm{g})$. The optmization experiments were carried out individually for aqueous solutions and solid media (INCT-5OBTL Tobacco Leaves). In both optimizations, the experiments were carried out in random order, employing $500 \mathrm{ng}$ Co as internal standard, $0.21 \mathrm{ng} \mathrm{Mo}$, and $4.25 \mathrm{ng} \mathrm{Ni}$. Integrated absorbance was measured in triplicate $(n=3)$ and used as the analytical response. The experimental data and the superimposed contour plot were processed using Statgraphics Centurion XVI v. 16.1.15 software. The method used a design of experiments based on multiple response optimization, enabling determination of the settings of the experimental factors that led to the desired characteristics, evaluating more than one response simultaneously. In this procedure, the responses for $\mathrm{Co}$, Mo, and Ni were considered individually for each 
experimental trial, and the mathematical function was constructed based on the experimental conditions and the response variable values. Maximization of the mathematical function corresponded to the optimum condition for simultaneous maximization of the responses for the three elements. The optimized values for the three variables, obtained by means of the factorial design, were used for the heating program of the graphite furnace in subsequent experiments.

After establishing the heating program, response curves were constructed in the 50-1200 ng Co mass range in order to determine the linear response interval and the suitable masses of Co for addition to the blanks, analytical solutions, and samples. Analytical curves for Mo and Ni were produced in the mass ranges $0-0.33 \mathrm{ng}$ and $0-8.50 \mathrm{ng}$, respectively, using aqueous standard solutions. The first point of the calibration curves $(0 \mathrm{ng})$ was established using the zero mass concept, by measuring the signals for firings of the empty platform.

The influence of matrix species on sensitivity was evaluated by means of calibrations in the mass range $0.1-1.0 \mathrm{mg}$, using the aqueous and solid media. Different masses $(0.1,0.3,0.5,0.8$, and $1.0 \mathrm{mg}$ ) of the INCT-OBTL-5 Oriental Basma Tobacco Leaves CRM were used as solid standards. Different aliquots $(2.0,6.0,10,16$, and $20 \mu \mathrm{L}$ ) of a solution containing $20 \mu \mathrm{g} \mathrm{L}^{-1}$ Mo and $425 \mu \mathrm{g} \mathrm{L}^{-1}$ $\mathrm{Ni}$ were used as aqueous standards. The aqueous and solid standards (and blanks) were spiked with $1000 \mathrm{ng}$ Co as internal standard for the Ni determinations. For each mass interval, the measurements were carried out in triplicate $(n=3)$.

The minimum mass was investigated using $0.05-1.0 \mathrm{mg}$ of INCT-OBTL-5 Tobacco Leaves CRM, in increments of $0.1 \mathrm{mg}$. Each mass interval represented the average weight of three samples.

For analysis by SS-HR-CS GFAAS, sample masses in the range $0.35-0.45 \mathrm{mg}$ were transferred to the platform, which was automatically weighed and introduced into the graphite furnace. Calibration curves were constructed using aqueous standard solutions for Mo and internal standardization for Ni. All the measurements were carried out in triplicate $(n=3)$.

\section{Results and discussion}

\subsection{Evaluation of the simultaneous measurement of co, mo, and ni}

Although the simultaneous determination of Mo and $\mathrm{Ni}$ in soil amendments and wine by HR-CS GFAAS has been described [21], the determination of $\mathrm{Ni}$ in plant materials is an analytical challenge, with preliminary studies showing that matrix effects can strongly limit accuracy and precision. The use of IS calibration was therefore evaluated in order to minimize such effects. Cobalt was selected as a potential internal standard for $\mathrm{Ni}$ analysis, considering similarities of the elements in terms of physico-chemical properties such as atomic mass, melting point, boiling point, enthalpy of fusion and formation of gaseous atoms, and oxide dissociation energy (Table 2) [22]. The HR-CS GFAAS instrumental arrangement included a charge-coupled device (CCD) detector capable of monitoring the neighborhood of the analytical line [23]. Despite the potential for multi-line monitoring [19], the simultaneous measurement of $\mathrm{Co}$, Mo, and $\mathrm{Ni}$ by HR-CS GFAAS has not yet been reported in the literature. Considering that the wavelength interval reaching the $\mathrm{CCD}$ close to the main line of Mo at $313.259 \mathrm{~nm}$ is $\pm 0.398 \mathrm{~nm}$ [24], atomic absorption lines within the $313.259 \pm 0.398 \mathrm{~nm}$ interval can be measured simultaneously. Fig. 1 shows that the main line of Mo at $313.259 \mathrm{~nm}$ and the alternative lines for $\mathrm{Co}$ at $313.221 \mathrm{~nm}$ and $\mathrm{Ni}$ at $313.410 \mathrm{~nm}$ were within the spectral range of the HR-CS GFAAS. The relative sensitivities of these $\mathrm{Co}$ and $\mathrm{Ni}$ lines, compared to the most sensitive lines for these elements, are 0.0083 and $4.8 \%$, respectively. The line
Table 2

Physicochemical properties of Co, Mo, Ni and their oxides [21].

\begin{tabular}{|c|c|c|c|}
\hline \multirow[t]{2}{*}{ Property } & \multicolumn{3}{|l|}{ Element } \\
\hline & Co & $\mathrm{Ni}$ & Mo \\
\hline Atomic mass & 58.933 & 58.693 & 95.94 \\
\hline Atomic radius (pm) & 125 & 125 & 136 \\
\hline Melting point $\left({ }^{\circ} \mathrm{C}\right)$ & 1495 & 1455 & 2623 \\
\hline Boiling point $\left({ }^{\circ} \mathrm{C}\right)$ & 2927 & 2913 & 4639 \\
\hline Enthalpy of fusion $\left(\mathrm{kJ} \mathrm{mol}^{-1}\right)$ & 16.20 & 17.48 & 37.48 \\
\hline $\begin{array}{l}\text { Enthalpy of formation of gaseous } \\
\text { atoms }\left(\mathrm{kJ} \mathrm{mol}^{-1}\right)\end{array}$ & 426.7 & $430.1 \pm 8.4$ & $658.98 \pm 3.8$ \\
\hline \multirow[t]{2}{*}{$\begin{array}{l}\text { Dissociation energy of } \mathrm{MO}_{(\mathrm{g})} \\
\quad\left(\mathrm{kJ} \mathrm{mol}{ }^{-1}\right)\end{array}$} & $384.5 \pm 13.4$ & $366 \pm 30$ & 502 \\
\hline & $\begin{array}{l}\text { Compound } \\
\mathrm{CoO}\end{array}$ & $\mathrm{NiO}$ & $\mathrm{MoO}_{2}$ \\
\hline Melting point $\left({ }^{\circ} \mathrm{C}\right)$ & 1933 & 1955 & 1100 \\
\hline
\end{tabular}

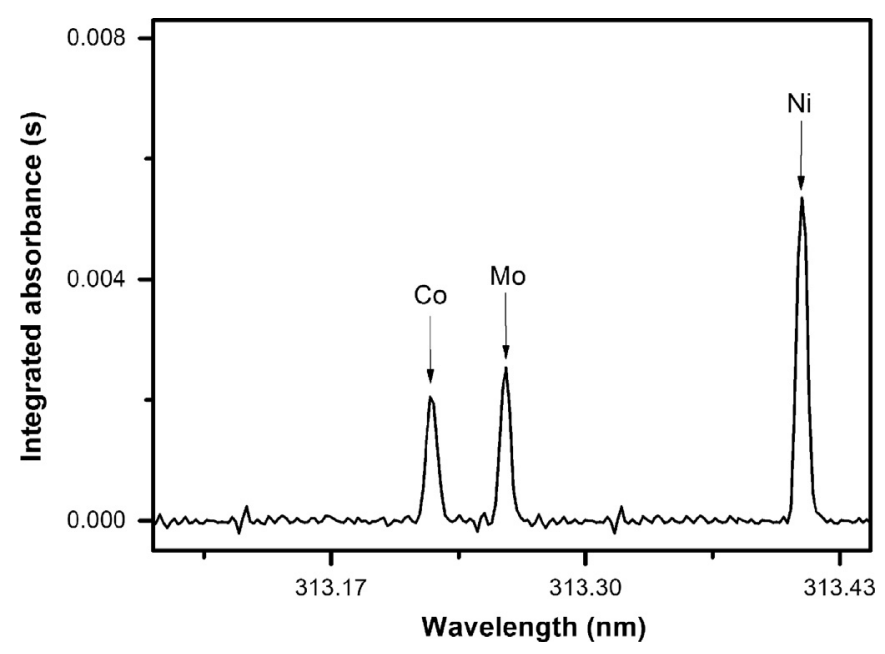

Fig. 1. Absorbance spectrum for $0.33 \mathrm{ng} \mathrm{Mo}, 6.8 \mathrm{ng} \mathrm{Ni}$, and $1000 \mathrm{ng}$ Co in the vicinity of the main Mo line at $313.259 \mathrm{~nm}$. Heating program as shown in Table 1.

at $313.221 \mathrm{~nm}$ is unsuitable for the determination of Co present at trace amounts in plant tissues. However, it is suitable for use in IS, because the amount of Co internal standard spiked into the blanks, standards, and samples can be considered constant, with the contribution of any Co naturally occurring in the samples being negligible. Despite the low relative sensitivity of the Ni line at $313.410 \mathrm{~nm}$, it is still suitable for determination of normal levels of $\mathrm{Ni}$ in plant tissues, in the range from 0.5 to $5 \mathrm{mg} \mathrm{kg}^{-1}$ (dry weight basis) $[25,26]$.

\subsection{Thermochemical behaviors of co, mo, and ni}

In DSS HR-CS GFAAS, calibration can be problematic due to the limited number of solid standards available. Nevertheless, this drawback can be circumvented by using calibration with aqueous standards, if a suitable atomizer heating program is developed. In GFAAS, single-element and multi-element methods employ only one atomizer heating program [13], so in simultaneous determinations the heating program is common for all analytes. Hence, the optimized pyrolysis and atomization temperatures might not coincide with the best temperatures for each analyte, and are usually a compromise in terms of sensitivity, precision, and accuracy. The thermochemical behaviors of $\mathrm{Co}, \mathrm{Ni}$, and Mo were evaluated by means of pyrolysis and atomization temperatures obtained using a $2^{3}$ factorial design for simultaneous response optmization. The levels were chosen considering the manufacturer's 
recommendations and data reported in the literature [14]. The absorbances obtained for the elements in solid media are presented in Table S1, from which it can be seen that similar responses were obtained for the aqueous and solid media.

Some of the main variables and their interactions presented significant effects (95\% confidence level, t-test). For Mo, the effects of all the variables and interactions were significant. For $\mathrm{Ni}$, a significant effect was only observed for the interaction between the pyrolysis and atomization temperatures, while for Co significant effects were observed for the chemical modifier and the pyrolysis temperature.

The experimental conditions and responses were used to generate a mathematical model and a superimposed contour plot (Fig. S1). This model enabled identification of the optimum pyrolysis and atomization temperatures that maximized the absorbance signals for the three elements simultaneously. The optimized analytical conditions were as follows: pyrolysis temperature of $1600^{\circ} \mathrm{C}$; atomization temperature of $2600{ }^{\circ} \mathrm{C}$; no addition of modifier. These conditions were adopted for use in the subsequent experiments.

\subsection{Evaluation of micro-homogeneity and sample size}

The precision and accuracy of solid sample analysis can depend on sample size [15]. A small amount of sample may be inhomogeneous and not representative of the entire material, while a large sample size may disturb the pyrolysis step and lead to underestimation. The influence of sample size on accuracy was evaluated by analyzing different masses $(0.05-1.0 \mathrm{mg})$ of the INCTOBTL-5 Tobacco Leaves CRM (Fig. S2). More accurate and precise results for Mo and $\mathrm{Ni}$ were obtained using masses in the range $0.35-0.45 \mathrm{mg}$. Masses of around $0.40 \mathrm{mg}$ were therefore weighed out throughout the experiments. The micro-homogeneity was evaluated by calculation of the homogeneity factor, $H_{e}$, for all mass intervals, using $H_{e}=S_{H} \cdot m^{1 / 2}$, where $S_{H}$ is the sampling error (estimated by the RSD of the measurements) and $m$ is the sample mass in milligrams [15]. Sample sizes with $H_{e}<10$ are considered homogeneous. The homogeneity factors calculated for Tobacco Leaves CRM masses of around $0.40 \mathrm{mg}$ were lower than 10 , suggesting that the CRM was sufficiently homogeneous for use in assessing the performance of the method.

The evaluation of micro-homogeneity and minimum mass was only performed for the INCT-OBTL-5 Tobacco Leaves CRM, because the precisions of the analyses of the samples and the other CRMs did not show any significant differences (95\% confidence level, Ftest).

\subsection{Evaluation of matrix effects and calibration of the method}

The use of aqueous standards in solid sample analysis is the easiest and simplest mode of calibration, provided variations in the sample matrices do not significantly disturb pyrolysis and atomization processes. The influence of the matrix on the absorbance of Mo and $\mathrm{Ni}$ was evaluated by comparing the slopes of analytical curves constructed in the $0-0.33 \mathrm{ng}$ Mo and $0-8.50 \mathrm{ng}$ $\mathrm{Ni}$ mass ranges using aqueous $\left(0.1 \%(\mathrm{v} / \mathrm{v}) \mathrm{HNO}_{3}\right)$ and solid (INCTOBTL-5 Oriental Basma Tobacco Leaves CRM) standards (Fig. 2). The figures of merit of the Mo and Ni calibrations are presented in Table 3. Calculations of characteristic masses $\left(m_{0}\right)$ and sensitivities were then used to assess the occurrence of matrix effects and to check the effectiveness of the optimized heating program. Despite the good linear correlation coefficients $(r)$ obtained between the absorbance values and the analyte concentrations (Mo: 0.9950 aqueous, 0.9991 - solid; Ni: 0.9988 - aqueous, 0.9982 - solid), the slopes of the analytical curves for these media were $0.017 \mathrm{~s} \mathrm{ng}^{-1}$ (Ni - aqueous), $0.026 \mathrm{~s} \mathrm{ng}^{-1}$ (Ni - solid), $0.35 \mathrm{~s} \mathrm{ng}^{-1}$ (Mo -
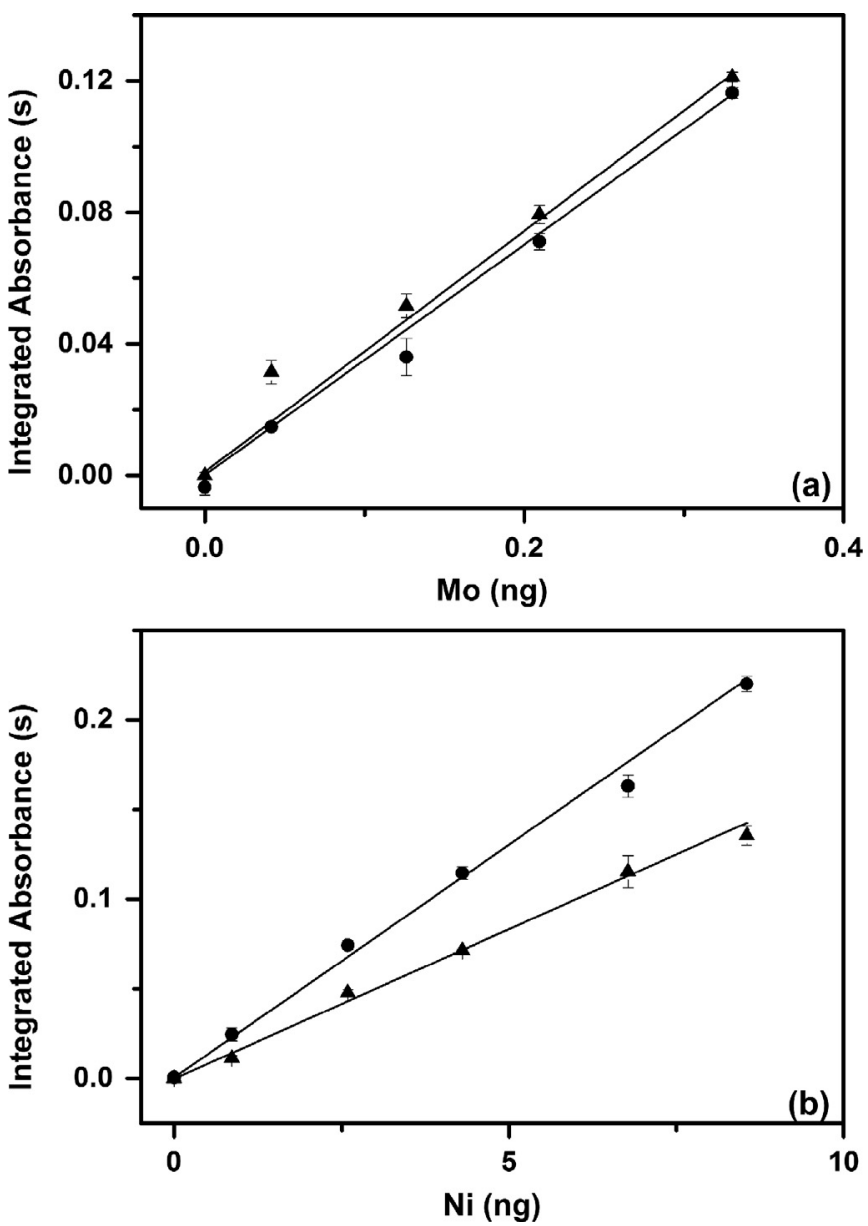

Fig. 2. Calibration curves for $\mathrm{Mo}(\mathrm{a})$ and $\mathrm{Ni}$ (b) constructed using aqueous solutions $(\bullet)$ and the INCT-OBTL-5 Oriental Basma Tobacco Leaves CRM $(\bullet)$. Heating program as shown in Table 1.

Table 3

Figures of merit for Mo and Ni determinations by DSS HR-CS GFAAS.

\begin{tabular}{lll}
\hline Parameter & Mo & $\mathrm{Ni}$ \\
\hline LOD (ng) & 0.018 & 0.025 \\
LOQ (ng) & 0.055 & 0.074 \\
$m_{0}$ (ng) & 0.12 & 0.017 \\
Linear working range (ng) & $0-0.33$ & $0-8.5$ \\
$r$ & 0.9950 & 0.9942 \\
\hline
\end{tabular}

aqueous), and $0.34 \mathrm{~s} \mathrm{ng}^{-1}$ (Mo - solid). The calculated characteristic masses for Mo in the aqueous and solid media were 0.012 and $0.013 \mathrm{ng}$, respectively, while the values for Ni were $0.26 \mathrm{ng}$ (aqueous) and $0.17 \mathrm{ng}$ (solid). Hence, matrix effects were more pronounced for Ni than for Mo. The errors associated with measurements of Mo and Ni in the solid plant CRM using the middle parts of the calibration curves obtained from aqueous standards were around $9.5 \%$ and $59 \%$, respectively. Therefore, the IS calibration procedure was used to minimize these effects in the Ni measurements. The working linear calibration range for Co, using the $313.221 \mathrm{~nm}$ line, was 50-1200 ng Co, with a correlation coefficient of 0.9998 . Hence, $1 \mu \mathrm{g}$ Co was added to the blanks, analytical standards, and samples in order to provide a better signal-to-noise ratio and 'mask' the naturally occurring Co in the samples. The influence of the Co internal standard was investigated by constructing curves in the $0-8.50 \mathrm{ng} \mathrm{Ni}$ range, using aqueous and solid standards spiked with $1 \mu \mathrm{g}$ Co. Good linear correlation coefficients between $\mathrm{A}^{\mathrm{Ni}} / \mathrm{A}^{\mathrm{Co}}$ and the $\mathrm{Ni}$ concentration (Fig. 3) were obtained 


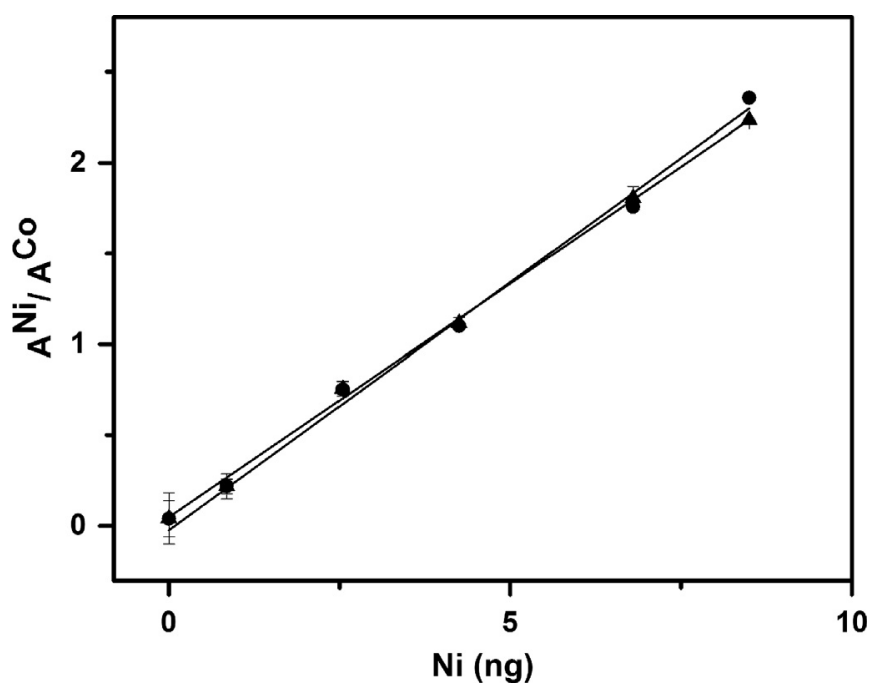

Fig. 3. Calibration curves obtained for Ni using aqueous solutions ( $\mathbf{\wedge}$ ) and the Tobacco Leaves CRM $(\bullet)$, with $1000 \mathrm{ng}$ Co internal standard. Heating program as shown in Table 1.

for both aqueous (0.9942) and solid (0.9993) media. The sensitivities obtained for aqueous and solid media were 0.299 and $0.286 \mathrm{~s} \mathrm{ng}^{-1}$, respectively. Using IS, the characteristic masses for $\mathrm{Ni}$ in the aqueous and solid media were 0.0170 and $0.0167 \mathrm{ng}$, respectively. Use of the calibration curves generated by IS resulted in errors $\leq 5 \%$, which is acceptable for foliar analysis. Therefore, all the determinations employed aqueous standards to construct external calibration and IS calibration curves for $\mathrm{Mo}$ and $\mathrm{Ni}$, respectively.

\subsection{Determination of mo and ni in CRMs and samples}

After optimization, the performance of the method was evaluated by means of simultaneous determination of Mo and $\mathrm{Ni}$ in six CRMs (Table 4). The results found for Mo were in agreement with the certified values of the CRMs (95\% confidence level, t-test). Analysis of the CRMs using IS provided results that were more accurate and precise, compared to those obtained without IS. Using Co as internal standard, the results for Ni were in agreement with the certified values (95\% confidence level, t-test). The agreement of the measured $\mathrm{Ni}$ concentrations in the CRMs with the certified values improved from $62-135 \%$ (without IS) to $94-$ $105 \%$ (with IS). Limits of quantification of 0.055 and $0.074 \mathrm{ng}$ were obtained for Mo and $\mathrm{Ni}$, respectively. The proposed method was applied in the determination of Mo and $\mathrm{Ni}$ in different types of plant materials used as renewable sources of energy (sugarcane leaves, banana tree fiber, soybean straw, coffee pods, orange bagasse, peanut hulls, and sugarcane bagasse). The concentrations found for Mo and Ni ranged from 0.08 to $0.63 \mathrm{ng} \mathrm{mg}^{-1}$ and from 0.41 to $6.92 \mathrm{ng} \mathrm{mg}^{-1}$, respectively. The precision of the measurements (RSD) varied from $2.1 \%$ to $11 \%$ for Mo and from $3.7 \%$ to $10 \%$ for $\mathrm{Ni}$. The results showed that the nickel and cobalt in the different matrices presented closely similar behavior, which was probably due to their similar mechanisms of atomization. Atomization processes in the graphite furnace can be influenced by many factors [27]. According to the literature, the main atomization routes for $\mathrm{Co}$ and $\mathrm{Ni}$ are the formation of their oxides, followed by the reduction of $\mathrm{CoO}_{(\mathrm{g})}$ or $\mathrm{NiO}_{(\mathrm{g})}$ by carbon, or oxide dissociation, generating $\mathrm{Co}_{(\mathrm{g})}$ and $\mathrm{Ni}_{(\mathrm{g})}[28,29]$. Similarities in atomization mechanisms and the effectiveness of $\mathrm{Co}$ as an internal standard in Ni determinations can also be explained considering the physico-chemical characteristics of the metals (Table 2).
Table 4

Results (mean \pm standard deviation) for Mo and $\mathrm{Ni}\left(\mathrm{ng} \mathrm{mg}^{-1}\right)$ determined $(n=3)$ in CRMs and plant materials by the proposed DSS HR-CS GF AAS method. Values in brackets means relative standard deviation.

\begin{tabular}{|c|c|c|c|}
\hline \multirow[t]{2}{*}{ Sample } & \multirow[t]{2}{*}{ Mo } & \multicolumn{2}{|l|}{$\mathrm{Ni}$} \\
\hline & & Without IS & With IS \\
\hline 1572 Citrus Leaves $^{a}$ & $0.14 \pm 0.01(7.1)$ & $0.79 \pm 0.03$ & $0.63 \pm 0.08$ \\
\hline 1547 Peach Leaves ${ }^{\mathrm{b}}$ & $0.055 \pm 0.004(7.3)$ & $0.43 \pm 0.06$ & $0.65 \pm 0.06(9.2)$ \\
\hline 1515 Apple Leaves ${ }^{c}$ & $0.094 \pm 0.006(6.3)$ & $1.23 \pm 0.05(4.1)$ & $0.88 \pm 0.04(4.5)$ \\
\hline $\begin{array}{l}\text { 1573a Tomato } \\
\text { Leaves }^{\mathrm{d}}\end{array}$ & $0.49 \pm 0.04(8.2)$ & $2.07 \pm 0.04(1.9)$ & $1.60 \pm 0.08(5.0)$ \\
\hline $\begin{array}{l}\text { INCT-OBTL-5 To- } \\
\text { bacco Leaves }^{\text {e }}\end{array}$ & $0.42 \pm 0.02(4.8)$ & $10.70 \pm 0.9(8.4)$ & $8.53 \pm 0.21(2.5)$ \\
\hline 1575a Pine Needles ${ }^{\mathrm{f}}$ & - & $1.32 \pm 0.08(6.1)$ & $1.40 \pm 0.12(8.6)$ \\
\hline Banana tree fiber & $0.19 \pm 0.02(10)$ & $<0.074$ & $<0.074$ \\
\hline Soybean straw 1 & $0.38 \pm 0.03(7.9)$ & $5.35 \pm 0.21(3.9)$ & $5.62 \pm 0.51(9.1)$ \\
\hline Soybean straw 2 & $0.63 \pm 0.03(4.8)$ & $0.87 \pm 0.14(16)$ & $1.04 \pm 0.04$ \\
\hline Coffee pods & $0.40 \pm 0.01(2.5)$ & $5.74 \pm 0.09(1.6)$ & $6.27 \pm 0.23(3.7)$ \\
\hline Orange bagasse & $0.17 \pm 0.01(5.9)$ & $<0.074$ & $<0.074$ \\
\hline Peanuts hulls 1 & $0.15 \pm 0.01(6.7)$ & $0.94 \pm 0.10$ & $0.96 \pm 0.04(4.2)$ \\
\hline Peanuts hulls 2 & $0.48 \pm 0.01(2.1)$ & $6.96 \pm 0.54(7.7)$ & $6.92 \pm 0.68(9.8)$ \\
\hline Sugarcane bagasse 1 & $0.08 \pm 0.003$ & $<0.074$ & $<0.074$ \\
\hline Sugarcane bagasse 2 & $0.18 \pm 0.02$ & $2.34 \pm 0.25(11)$ & $2.56 \pm 0.27(10)$ \\
\hline Sugarcane leaves & $0.54 \pm 0.04(7.4)$ & $0.45 \pm 0.15$ & $0.41 \pm 0.04$ \\
\hline
\end{tabular}

a Certified value: $0.17 \pm 0.09 \mathrm{ng} \mathrm{mg}^{-1} \mathrm{Mo}, 0.60 \pm 0.30 \mathrm{ng} \mathrm{mg}^{-1} \mathrm{Ni}$.

${ }^{\mathrm{b}}$ Certified value: $0.060 \pm 0.008 \mathrm{ng} \mathrm{mg}^{-1} \mathrm{Mo}, 0.69 \pm 0.09 \mathrm{ng} \mathrm{mg}^{-1} \mathrm{Ni}$.

${ }^{c}$ Certified value: $0.094+0.013 \mathrm{ng} \mathrm{mg}^{-1} \mathrm{Mo}, 0.91+0.12 \mathrm{ng} \mathrm{mg}^{-1} \mathrm{Ni}$.

${ }^{\mathrm{d}}$ Information value: $0.46 \mathrm{ng} \mathrm{mg}^{-1} \mathrm{Mo}$, certified value: $1.59 \pm 0.07 \mathrm{ng} \mathrm{mg}^{-1} \mathrm{Ni}$.

e Certified value: $0.41 \pm 0.062 \mathrm{ng} \mathrm{mg}^{-1} \mathrm{Mo}, 8.5 \pm 0.49 \mathrm{ng} \mathrm{mg}^{-1} \mathrm{Ni}$.

${ }^{f}$ Certified value: $1.47 \pm 0.10 \mathrm{ng} \mathrm{mg}^{-1} \mathrm{Ni}$.

\section{Conclusions}

The proposed method based on DSS HR-CS GFAAS was effective for the simultaneous determination of Mo and Ni in different plant materials. Factorial design was used as a valuable tool to not only optimize the heating program, but also economize in terms of cost and time during development of the method. The construction of calibration curves using aqueous and solid media revealed the existence of matrix effects in the Ni determination. The use of Co as internal standard was able to eliminate these interferences, due to the similarities between the elements in terms of their physicochemical properties and atomization mechanisms. It was therefore possible to employ conventional aqueous calibration in solid sample analysis of Mo and $\mathrm{Ni}$, since matrix effects were minimal for Mo. The method is environmentally friendly because the use of direct solid sample analysis significantly reduces the environmental impacts associated with use of the hazardous reagents commonly employed for sample preparation. The technique should be useful in laboratories conducting routine foliar analyses, since the monitoring of Mo and $\mathrm{Ni}$ can contribute to increased productivity of crops and other biomasses.

\section{Acknowledgments}

The authors would like to thank Fundação de Amparo à Pesquisa do Estado de São Paulo (FAPESP) for financial support of this work (Grant \#2014/12595-1). The authors are also grateful to Coordenação de Aperfeiçoamento de Pessoal de Nível Superior (CAPES) (Grant \# 33004030072P8) for fellowships to D.V.B., and to Conselho Nacional de Desenvolvimento Científico e Tecnológico (CNPq) (Grant \#471453/2013-7) for fellowships to A.I.B. and M.A.B. and a research fellowship to J.A.G.N. 


\section{Appendix A. Supplementary material}

Supplementary data associated with this article can be found in the online version at http://dx.doi.org/10.1016/j.talanta.2016.02. 046.

\section{References}

[1] M.E. Farago, A. Mehra, Plants and the Chemical Elements, Wiley-VCH, Weinheim, 1994.

[2] D. Giovanni, A.D. Giacomo, Citrus: The Genus Citrus, CRC Press, Boca Raton, 2002.

[3] K. Mengel, K.A. Ernest, Principles of Plant Nutrition, Kluwer Academic Publishers, Dordrecht, 2001.

[4] F. Bittner, Molybdenum metabolism in plants and crosstalk to iron, Front. Plant Sci. 5 (2014) 1-6.

[5] M. Tejada-Jimenez, A. Chamizo-Ampudia, A. Galvan, E. Fernandez, A. Llamas, Molybdenum metabolism in plants, Metallomics 5 (2013) 1191-1203.

[6] W. Zimmer, R. Mendel, Molybdenum metabolism in plants, Plant Biol. 1 (1999) 160-168.

[7] J.C. Polacco, P. Mazzafera, T. Tezottoc, Nickel and urease in plants: still many knowledge gaps, Plant Sci. 199 (2013) 79-90.

[8] I.V. Seregin, A.D. Kozhevnikova, Physiological role of nickel and its toxic effects on higher plants, Russ. J. Plant Physiol. 53 (2006) 257-277.

[9] M. van Maarschalkerweerd, S. Husted, Recent developments in fast spectroscopy for plant mineral analysis, Front. Plant Sci. (2015), http://dx.doi.org/ 10.3389/fpls.2015.00169.

[10] D. Tilman, K.G. Cassman, P.A. Matson, R. Naylor, S. Polasky, Agricultural sustainability and intensive production practices, Nature 418 (2002) 671-677.

[11] J.C. de Andrade, A.M. de Almeida, L.M. Aleixo, A.R. Coscione, M.F. de Abreu, Direct voltammetric determination of $\mathrm{Mo}(\mathrm{VI})$ in plants: the need for a multivariate study of interferences, Anal. Chim. Acta 487 (2003) 243-248.

[12] R. Dobrowolski, M. Otto, Determination of nickel and cobalt in reference plants materials by carbon slurry sampling GFAAS technique after their simultaneous preconcentration onto modified active carbon, J. Food Compos. Anal. 26 (2012) 58-65.

[13] D.J. Butcher, J. Sneddon, A Practical Guide to Graphite Furnace Atomic Absorption Spectrometry, John Wiley \& Sons, New York, 1998.

[14] B. Welz, M. Sperling, Atomic Absorption Spectrometry, Wiley-VCH, Weinheim, 1999.
[15] U. Kurfürst, Solid Sample Analysis: Direct and Slurry Sampling Using GF AAS and ETV-ICP, Springer, Berlin, 1998.

[16] M. Resano, E. García-Ruiz, High-resolution continuum source graphite furnace atomic absorption spectrometry: is it as good as it sounds? A critical review, Anal. Bioanal. Chem. 399 (2011) 323-330.

[17] B. Welz, D.L.G. Borges, F.G. Lepri, M.G.R. Vale, U. Heitmann, High-resolution continuum source electrothermal atomic absorption spectrometry - an analytical and diagnostic tool for trace analysis, Spectrochim. Acta B 62 (2007) $873-883$.

[18] U. Heitmann, B. Welz, D.L.G. Borges, F.G. Lepri, Feasibility of peak volume, side pixel and multiple peak registration in high-resolution continuum source atomic absorption spectrometry, Spectrochim. Acta B 62 (2007) 1222-1230.

[19] B. Welz, H. Becker-Ross, S. Florek, U. Heitmann, High-Resolution Continuum Source AAS. The Better Way to Do Atomic Absorption Spectrometry, WileyVCH, Weinheim, 2005

[20] M.A. Bechlin, F.M. Fortunato, E.C. Ferreira, J.A. Gomes Neto, J.A. Nóbrega, G. L. Donati, B.T. Jones, Bismuth as a general internal standard for lead in atomic absorption spectrometry, Anal. Chim. Acta 831 (2014) 24-30.

[21] W. Boschetti, A.R. Borges, A.T. Duarte, M.B. Dessuy, M.G.R. Vale, J.B. de Andrade, B. Welz, Simultaneous determination of Mo and Ni in wine and soil amendments by HR-CS GF AAS, Anal. Methods 6 (2014) 4247-4256.

[22] D.R. Lide (Ed.), CRC Handbook of Chemistry and Physics, CRC Press, Boca Raton, 2007.

[23] B. Gómez-Nieto, M.J. Gismera, M.T. Sevilla, J.R. Procopio, Simultaneous and direct determination of iron and nickel in biological solid samples by highresolution continuum source graphite furnace atomic absorption spectrometry, Talanta 116 (2013) 860-865.

[24] M. Resano, L. Rello, M. Flórez, M.A. Belarra, On the possibilities of high-resolution continuum source graphite furnace atomic absorption spectrometry for the simultaneous or sequential monitoring of multiple atomic lines, Spectrochim. Acta B 66 (2011) 321-328.

[25] E. Malavolta, Manual de Química Agrícola, Agronômica Ceres, São Paulo, 1976

[26] E. Malavolta, M.F. Moraes, Nickel - from toxic to essential nutrient, Better Crops Plant Food 91 (2007) 26-27.

[27] W. Frech, A.O. Lindberg, E. Lundberg, A. Cedergren, Atomization mechanisms and gas phase reactions in graphite furnace atomic absorption spectrometry, Fresenius Z. Anal. Chem. 323 (1986) 716-725.

[28] C.L. Chakrabarti, S.J. Cathum, Mechanism of cobalt atomization from different atomizer surfaces in graphite-furnace atomic-absorption spectrometry, Talanta 37 (1990) 1111-1117.

[29] J. Alvarado, The mechanism of atomisation of iron, cobalt and nickel during electrothermal atomisation atomic absorption spectrometry, Quim. Anal. 15 (1996) 173-177. 